\title{
JUECES CRONOPIOS Y JUECES FAMAS
}

\author{
Jaime Francisco Coaguila Valdivia*
}

\section{Resumen}

El libro de Julio Cortazar, Historia de Cronopios y Famas, fue escrito para luchar contra el pragmatismo, lo prefabricado y la solemnidad, particularidades en las que muchas veces vemos identificado el sistema judicial.

Realizando un análisis metafórico aplicado al derecho, se expone las falencias, prejuicios y rigurosidades del rol de los magistrados, haciendo una contraposición de los llamados jueces cronopios y jueces famas dentro de un panorama judicial.

Palabras clave: Jueces - magistrados - judicatura - sistema judicial.

\begin{abstract}
The book History of cronopios and famas by Julio Cortazar was written to fight against the pragmatism, the pre made and the solemnity, characteristics than more than once identified the Judicial Power.

Making a metaphorical analysis applied to the right, it is expose the lacks, prejudices and rigors of the roll of the magistrates, doing a contrast of the calls cronopios judges and judges fame within a judicial view.
\end{abstract}

Key words: Judges - magistrales - judicature - judicial system.

\section{Sumario}

1. Fase mitológica de la judicatura. 2. El baile de los jueces famas. 3. El canto de los jueces cronopios.

\footnotetext{
* Juez Especializado Provisional de la Corte Superior de Justicia de Arequipa - Poder Judicial de Perú. Profesor
} de la Universidad Católica de Santa María de Arequipa. 


\section{FASE MITOLÓGICA DE LA JUDICATURA}

El escritor argentino Julio Cortázar rememora que la idea de escribir el libro "Historias de Cronopios y de Famas" (1962) surgió una noche durante un concierto en el teatro Des Champs Elysées cuando vio flotar a su alrededor unos globos de color verde y húmedos, a los que inmediatamente bautizó como cronopios ${ }^{1}$, luego surgirían casi por contraposición los famas y las esperanzas. Muchos se preguntarán qué relación puede mediar entre aquella clasificación casi mitológica propia de los juegos cortazarianos y la formalidad inherente a la magistratura, lo cierto es que el libro de Cortázar fue escrito para luchar contra el pragmatismo, lo prefabricado, las ideas congeladas por el abuso, los prejuicios y sobretodo la bestia negra de la solemnidad que a veces también prolifera en el ámbito judicial².

Para Cortázar los juegos son un refugio para la sensibilidad y la imaginación y donde los seres delicados se defienden de las aplanadoras sociales para luchar contra el pragmatismo y la horrible tendencia a la consecución de fines útiles ${ }^{3}$. Es por ello propicio anotar que en esa misma medida la judicatura se encuentra actualmente atrapada por el conservadurismo ante un mundo incomprensible, absurdo y lleno de peligros; por lo que es indispensable imprimir una nueva tónica al trabajo legal que supere la fase mitológica de una judicatura caracterizada por la sujeción al texto expreso de la ley y el concepto de neutralidad científica e ideológica.

El modelo del juez iberoamericano debe nutrirse literariamente del espíritu cortazariano y asumir que la vida puede ser mensurable por un termómetro, donde los seres humanos pueden clasificarse de acuerdo a sus interacciones con el entorno social que los rodean; así los cronopios son aquellos que tienen el alma de los artistas y la poesía en sus actos; los famas son los personajes burgueses y los aburridos funcionarios del sistema; y las esperanzas se asimilan a aquellos "snobs" que no saben donde ubicarse en el mundo, pero que les gusta estar al lado de lo prestigioso ${ }^{4}$. Dentro de este contexto un cronopio es considerado ligeramente super-vida, un fama infra-vida y una esperanza para-vida ${ }^{5}$. Ahora bien, esta misma lógica aplicada al modelo de juez determina que existan jueces famas, jueces cronopios y jueces esperanzas, aunque para efectos de este ensayo resulte mejor contraponer los jueces positivista (famas) a los jueces poetas (cronopios) en una clara defensa de la super-vida o tal vez de la poesía de la justicia en perjuicio de los rigores formales de la ley. 


\section{EL BAILE DE LOS JUECES FAMAS}

Cuenta Cortázar que "cuando los famas salen de viaje, sus costumbres al pernoctar en una ciudad son las siguientes: Un fama va al hotel y averigua cautelosamente los precios, la calidad de las sábanas y el color de las alfombras. El segundo se traslada a la comisaría y labra un acta declarando los muebles e inmuebles de los tres, así como el inventario del contenido de sus valijas. El tercer fama va al hospital y copia las listas de los médicos de guardia y sus especialidades" ${ }^{\prime \prime}$. Esto demuestra que los famas dentro del cronómetro de vidas moran esclavos de la realidad y sus vicisitudes, por lo que su rol dentro de la sociedad solamente puede ser justificativo del orden impuesto, los famas confían ciegamente en los relojes y están siempre prestos a suprimir el azar mediante la extrema planificación, dejan poco a la improvisación y prefieren cumplir con su trabajo antes que soñar o imaginarse siquiera que existe la felicidad.

Los jueces famas son aquellos funcionarios de la justicia empeñosos y comprometidos con su labor, cumplen con fidelidad su Despacho diario y acatan sin arrepentimientos la normatividad vigente, no confían en el azar judicial ni en la dinámica de los juegos de poder, y se consideran una importante pieza dentro de una maquinaria articulada por miles de servidores públicos famas que de manera incansable redactan resoluciones en oficinas apretadas y poco iluminadas. Para los jueces fama lo que importa es el cumplimiento del deber, el respeto al texto expreso de la ley y el funcionamiento obediente del sistema judicial de acuerdo al modelo económico en boga, los jueces fama son los guardianes de la seguridad jurídica y los más severos defensores del procedimentalismo.

Si bien es cierto Cortázar ha precisado que la denuncia a través de los famas a la burguesía frente a la libertad y la poesía no ha sido deliberada ${ }^{7}$, no obstante la contraposición entre jueces cronopios y jueces famas permite extraer algunas conclusiones acerca del rol de los magistrados dentro del panorama judicial. En principio los jueces famas se pueden asimilar al paradigma de los jueces en tanto servidores neutros de la ley, porque su rol solamente consiste en eliminar las dificultades que se oponen a la autorregulación mercantil y al orden público económico ${ }^{8}$, para ello los juristas de Estado adoptan al positivismo jurídico y pueden considerarse "mera boca de la ley"; y en segundo lugar, los jueces fama como infra-vida también son infra-Derecho y por tanto infra-justicia, de tal forma que su rol de cumplimiento de la ley carece de innovaciones y poco aporta a la transformación de una sociedad moldeada al ritmo de una normatividad injusta. 
Pero aunque parezca increíble los jueces fama también albergan muy dentro de sí algunos valores inmateriales y una dosis de alegría cronopial que de vez en cuando los obliga a cantar y moverse cogidos de las manos al compás del catalá/tregua/espera9 ${ }^{9}$, esta danza conocida como baile de los famas permite recobrar las ilusiones de que el Derecho no se ha perdido en medio de la razón estratégica y que es muy probable que incluso los jueces famas a veces sueñen con un mundo de super-vida y por qué no de super-justicia.

\section{EL CANTO DE LOS JUECES CRONOPIOS}

Cuando un cronopio encuentran una flor solitaria en medio de los campos, juega alegremente con la flor, le acaricia los pétalos, la sopla para que baile, zumba como una abeja, huele su perfume y finalmente se acuesta debajo de la flor y se duerme envuelto en una gran paz ${ }^{10}$.

Esta historia demuestra hasta que punto los cronopios celebran la vida a pesar de todos sus inconvenientes y en qué medida descuidan la planificación y la racionalidad de los famas, para en su reemplazo adorar las emociones vitales y al simple sol de cada mañana. Los cronopios son como flores, porque se muestran bellos en todo momento y cantan canciones como si el cielo fuera una bandeja, a pesar de que debido a su entusiasmo se dejen atropellar por camiones y ciclistas, caigan por la ventana, pierdan lo que llevaban en los bolsillos y hasta la cuenta de los días ${ }^{11}$.

Por su parte los jueces cronopios no se desaniman por un mundo plagado de injusticias, donde el sistema constituye el principal obstáculo para revertir el culto al procesalismo, sino más bien sueñan un mundo mejor con una justicia bella y equitativa. Los jueces cronopios resuelven los casos apelando a la inteligencia emocional, los sentimientos humanos y la imaginación literaria al amparo de una gran responsabilidad social; para llegar a conseguir una super-justicia que trascienda los límites del positivismo jurídico anclado en reiteradas discusiones y extravíos técnicos a veces inútiles.

A la razón estratégica los jueces cronopios oponen la razón lúdica, no en vano el propio Cortázar ha señalado que el origen del libro se compara a un partido de tenis ${ }^{12}$, una metáfora que aplicada al Derecho puede sugerir que el fenómeno jurídico puede ser entendido como un juego en el que el azar tiene un rol importante en las decisiones. En este punto se impone la necesidad de un juez intérprete en un universo babélico de múltiples discursos e inmerso en medio de una red de innumerables significados producidos por heterogéneos 
centros de poder, un problema que resulta inmanejable para un juez fama pero que estimula la imaginación poética de un juez cronopio.

La justicia cronopial se enfrenta directamente a la justicia formal de los famas y el derecho cronopial desconstruye la lógica deductiva del derecho fama, una dialéctica que tiene su punto de confluencia en el preciso momento en que los jueces cronopios cantan y los jueces fama bailan su célebre catalá/ tregua/catalá, este punto de comunicación a través del arte revela que es posible reconstruir una justicia humana en base a la super-vida.

Los jueces cronopios pueden encontrar también a la justicia en medio de los campos, acariciar dulcemente sus pétalos y de pronto acostarse a su lado envuelto en una gran paz.

El final de una justicia cronopial no es sorprendente sino más bien una epifanía cotidiana, una alegoría de lo simple, como un grupo de globos verdes y húmedos flotando en un universo jurídico hecho de vertiginosas comunicaciones.

\footnotetext{
Prego, Omar. La Fascinación de las Palabras: Conversaciones con Julio Cortázar. Barcelona: Muchnik Editores, 1985. Pág. 123.

Vargas Llosa, Mario. La Trompeta de Deyá. Vid. www.geocities.com/wongcampos/195mvllcortazar.pdf Ibidem.

Prego, O. Op. Cit. Pág. 123.

Prego, O. Op. Cit. Pág. 135.

Cortázar, Julio. Historias de Cronopios y de Famas. 2da. Ed. Grupo Santillana Ediciones S.A., 2000. Pág. 131.

7 Prego, O. Op. Cit. Pág. 125.

8 Capella, Juan Ramón. Fruta Prohibida. Una aproximación histórico-teorética al estudio del Derecho y del Estado. 4ta Ed. Madrid: Editorial Trotta, 2006. Pág. 155.

9 Cortázar, Julio. Op. Cit. Pág. 123.

10 Cortázar, Julio. Op. Cit. Pág. 146.

11 Cortázar, Julio. Op. Cit. Pág. 141.

12 Prego, O. Op. Cit. Pág. 134.
} 